\title{
An Operative X-band Mini-radar Network to Monitor Rainfall Events with High Time and Space Resolution
}

\author{
S. Bertoldo \\ C. Lucianaz \\ O. Rorato \\ M. Allegretti \\ CINFAI (Consorzio Interuniversitario per la Fisica delle Atmosfere \\ e delle Idrosfere), presso DET (Dipartimento di Elettronica e \\ Telecomunicazioni), Politecnico di Torino \\ Corso Duca degli Abruzzi, 10129, Torino, Italy. \\ silvano.bertoldo@polito.it, claudio.lucianaz@polito.it
}

\author{
A. Prato \\ G. Perona \\ Envisens Technologies s.r.1. \\ spinoff del Politecnico di Torino \\ Località Baraggino presso Campus \\ Tecnologico 10034, Chivasso (TO), Italy. \\ andrea.prato@polito.it
}

\begin{abstract}
The increasing frequency of extreme and very localized precipitation events have been causing landslides, floods and casualties, especially in Sicily, due to its complex orography, and to the presence of densely inhabited areas just at the mouth of small basins. In order to monitor such phenomena with the needed high resolution in time and space, an experimental network of $\mathrm{X}$-band mini-radars, exclusively devoted to monitor rain, has been installed in some parts of Sicily since November 2010. The network is made up by 4 mini weather radars able to acquire a rain map every minute (or even at shorter intervals) with a radial space resolution better than $100 \mathrm{~m}$ within a range of up to $30 \mathrm{~km}$. Their low cost and the easiness of installation make such radars ideal for monitoring small areas or even just limited angular sectors, since it is more convenient to install more than one instrument instead of choosing special site locations or spending for installation support. The raw data are immediately processed in real time by the software installed on each radar unit, Cartesian maps are locally produced, compressed and transmitted via GPRS to a server where ad hoc products for the users are prepared and made available on a web site. A few examples of final products and some comparisons with rain gauges are presented.
\end{abstract}

Keywords - X band radar; radar meteorology; high time resolution; high space resolution; rainfall events

\section{INTRODUCTION}

The frequency of high intensity rainfall events is steadily increasing in the Mediterranean area and especially in the hilly and mountainous parts of Italy. Just in two months, October and November 2011, three serious floods occurred. On the 25th October 2011, in the La Spezia province and in Lunigiana, 520 $\mathrm{mm}$ of rain fell in less than 6 hours causing floods and the death of eight people. On 4th November 2011 a dramatic flood occurred over the city of Genoa with $400 \mathrm{~mm}$ rainfall falling in just a few hours. Six people died during this flood [1]. On 22nd November 2011, more than $200 \mathrm{~mm}$ of rain fell over the province of Messina (Sicily) where four people died [2].

In these situations, in order to efficiently monitor river flow, floods and landslides an unrealistic extremely dense rain gauge network is needed, considering the nature of the localized rain events of limited extension and the size of the river basins of interest. Alternatively, C-band or S-band meteorological radars are able to monitor rain fields over wide areas, but with not enough space and time resolution, and with high purchase and maintenance costs.

Indeed, in these last years, X-band meteorological radars are beginning to appear $[3,4]$. The radars described in [4] are certainly simpler (non-coherent, pulsed, one polarization only, non-Doppler, with a fixed elevation), but exclusively devoted to rain measurements (able to produce one rain map in a few seconds). Furthermore, their extremely low cost, the lack of any special installation needs, practically maintenance-free and the possibility to be remotely controlled with software adjournments, make them able to conveniently cover limited areas or even just limited angular sectors, since it is less expensive and time consuming to install more than one near-by instrument instead of choosing special site locations and spending for installation .

The studies and researches about the X-band mini weather radar started during the FORALPS ("Meteo-hydrological Forecast and Observations for improved water Resource management in the ALPS") project in 2004 [5, 6] and the network described in this paper is the first fully operational one. The experimental network installed in Sicily consists of 4 $\mathrm{X}$-band mini radars designed and installed by the local operative unit of CINFAI at Polytechnic of Turin (Consorzio Interuniversitario Nazionale per la Fisica delle Atmosfere e delle Idrosfere), in collaboration with Envisens Technologies s.r.l. spinoff of Polytechnic of Turin, through a cooperative project with the Civil Protection of the Regional Province of Palermo and the Regional Civil Protection of Sicily. The first radar is located in Palermo, the second and the third one are installed in Bisacquino (PA) and Gangi (PA) and the last one in Roccafiorita (ME). All the sites have been chosen in agreement with the Civil Protection of the Regional Province of Palermo and the Regional Civil Protection of Sicily. The radar units, installed from November 2010 to March 2011, after a first calibration period are now completely operative and transmit the Cartesian rain maps to a server maintained by the CINFAI. In order to further reduce the overall operational costs only free and open source software solutions have been used and tailored to the specific needs. 


\section{NETWORK TECHNICAL DESCRIPTION}

Table I reports the main technical specifications of the radars and two radars are shown in Figure 1. Considering their compactness, it should be noted that all the electronic equipments (antenna, radiofrequency unit, the data processing unit, the communication unit for data transmission and remote control, the power unit) are placed inside the radome. The radome itself may be secured to any flat surface and it needs to be connected with a power supply (less than $200 \mathrm{~W}$ at $220 \mathrm{~V}$ ).

TABLE I. MICRO WEATHER RADAR UNIT TECHNICAL SPECIFICATIONS

\begin{tabular}{|l|l|}
\hline \multicolumn{1}{|c|}{ Radome } & \\
\hline Height & $150 \mathrm{~cm}$ \\
\hline Diameter & $90 \mathrm{~cm}$ \\
\hline Material & Polyester \\
\hline \multicolumn{1}{|c|}{ Transmitter } & \\
\hline \multicolumn{1}{|c|}{ Receiver } & $10 \mathrm{~kW}$ \\
\hline Peak power & $600 \mathrm{~ns}$ \\
\hline Pulse length & $(9410 \pm 30) \mathrm{MHz}$ \\
\hline Transmitted frequency & $800 \mathrm{~Hz}$ \\
\hline Pulse Repetition Frequency (PRF) & Solid state \\
\hline Modulator & \\
\hline & \\
\hline & Logarithmic, solid state \\
\hline Receiver type & From 0 to $-100 \mathrm{dBm}$ \\
\hline Dynamic range & $60 \mathrm{MHz}$ \\
\hline Intermediate Frequency (IF) & $(20 \pm 2) \mathrm{MHZ}$ \\
\hline Receiver filter bandwidth & \\
\hline & \\
\hline Other technical specifications & $\begin{array}{l}\text { Microwave } \\
\text { circuit }\end{array}$ \\
\hline Front end & $<3.5 \mathrm{~dB}$ \\
\hline Noise figure & $\begin{array}{l}\text { Ferrite circulator with state } \\
\text { solid diode limiter }\end{array}$ \\
\hline Duplexer & $(22 \pm 2) \mathrm{r}$ p. $\mathrm{m}$. \\
\hline Antenna rotation speed & $24 \mathrm{Vdc}$ \\
\hline Power & \\
\hline
\end{tabular}

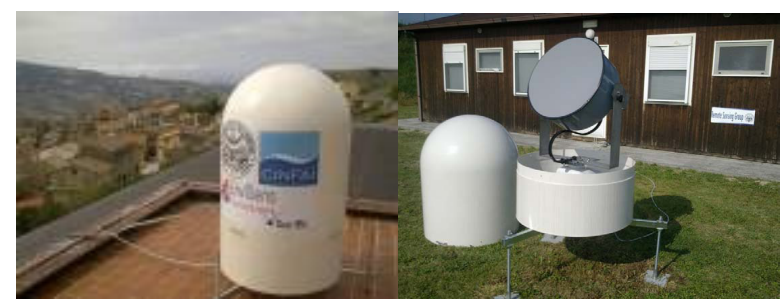

Fig. 1. The $\mathrm{X}$ band mini radar with and without the radome

The radar controller operating system is GNU Linux, Debian distribution. This choice allows great reliability and flexibility in the configuration and full control of active processes and packages. In addition it allows easy future increase of the number of radar units of the network simply by replicating the pre-configured software package without the need for subscription for new licenses. The server in the central unit stores the radar maps in a database. The same server has two more functions:

- it acts as a web server, in order to provide web services that can be browsed by users
- $\quad$ it also acts as a ftp server, allowing selected access from expert operators wishing to do their own data analysis.

The radar maps produced by each radar unit are transmitted to the server via a GPRS communication network: a ftp connection to the server is open and each map is transferred. Scheduled software running at specific time intervals manages data stored in the database in order to compute precipitation maps. All software has been developed partly in $\mathrm{C}$ and partly by using bash scripting and process scheduling. Web services have been developed with PHP and Javascript functions.

\section{SIGNAL PROCESSING}

The next two paragraphs describe the main processing steps, performed in each radar unit and in the server.

\section{A. Data acquisition and processing in the radar unit}

Every $3 \mathrm{sec}$ a georeferenced radar map of $4096 \times 2048$ data (respectively in range and azimuth) is acquired. If the antenna lobe is blocked by buildings or mountains, it is possible to inhibit the pulse generation and transmission in the corresponding angular regions (the so-called "blanked regions").

Raw data are expressed in 8 bit DN (Digital Numbers), covering the signal range from -100 to $0 \mathrm{dBm}$, and are generated from the analog to digital converter operating at 120 $\mathrm{MHz}$. Only 1 out of 3 data are taken to form the above georeferenced map. These data are immediately processed with an "anti-bang" filter to remove signal spikes due to interference with other pulsed radars, located near-by, and operating at the same frequency, and then transformed from logarithmic to linear scale.

All the maps collected in one minute are averaged into a new matrix with the same size of $4096 \times 2048$. A series of anti-clutter filters is then applied to the data to recover, as far as possible, rain signature even in presence of clutter. A first anti-clutter filter is based on a matrix where different threshold values are defined for each matrix cell ("pixel"). Each threshold value is represented by the median value of such cell with the addition of a constant term. The matrix is automatically and dynamically modified in time. The choice of the median as a threshold is to be preferred to the average since it is more statistically sensitive in the presence of extreme values. The adaptive threshold matrix is formed when the radar unit is turned on for the first time. Each day the computed threshold matrix is stored on the control pc of the radar unit to avoid the threshold adaptive computation process to start from the beginning in case of system power failure. A second anti-clutter filter is then applied in order to exploit the high range resolution available. Sequences of pixels along each ray with values greater than zero are considered: sequences with a length shorter than a fixed constant are removed since it is assumed that rain events have a bigger spatial correlation 
From this still polar matrix is derived a Cartesian $1024 \times$ 1024 matrix, where each value is the average of the polar pixels whose center of mass is falling within the considered Cartesian pixel. It is to be noted that each Cartesian pixel has a "virtual" dimension of $60 \times 60$ square meters: of course only the original physical range resolution is of the same order (approximately $90 \mathrm{~m}$ ) while the average range resolution is much larger (at 30 $\mathrm{km}$ range it is approximately $1500 \mathrm{~m}$ ), however in this way at least some of the detailed information present in the original range resolution data may still be preserved in the final data.

Finally, the data are transformed back in logarithmic units, compressed, and sent via ftp to the server for the next processing steps.

\section{B. Radar map processing at the server}

At the server, the maps are stored as DN in the data base with all the needed ancillary data added, and a last anti-clutter filter is adopted: a square matrix of $21 \times 21$ pixels centered on each pixel of the matrix is examined; if the number of non zero pixels in the matrix is less than a given constant (fixed, after a calibration period, at 150), the central pixel is put to zero. Before passing to the web presentation, $D N$ values are converted into reflectivity $\mathrm{Z}$ and into rainfall rate $\mathrm{R}$ through a $\mathrm{Z}-\mathrm{R}$ equation [7]. Finally, images are processed in order to be plotted on the web services, as shown in Figure 2, where the rainfall pixels are colored, the zero rain pixels are left transparent and the blanked areas are painted gray. It should be noted that web services present rain rate maps constructed with a chosen radar equation assumed appropriate for the rain typology examined, however the database still contains DN values, that can be retrieved and processed using different relations.

\section{WEB SERVICES}

Processed real time radar maps can be browsed on the official network web site where they are projected over a common cartographic system as shown in Figure 2.

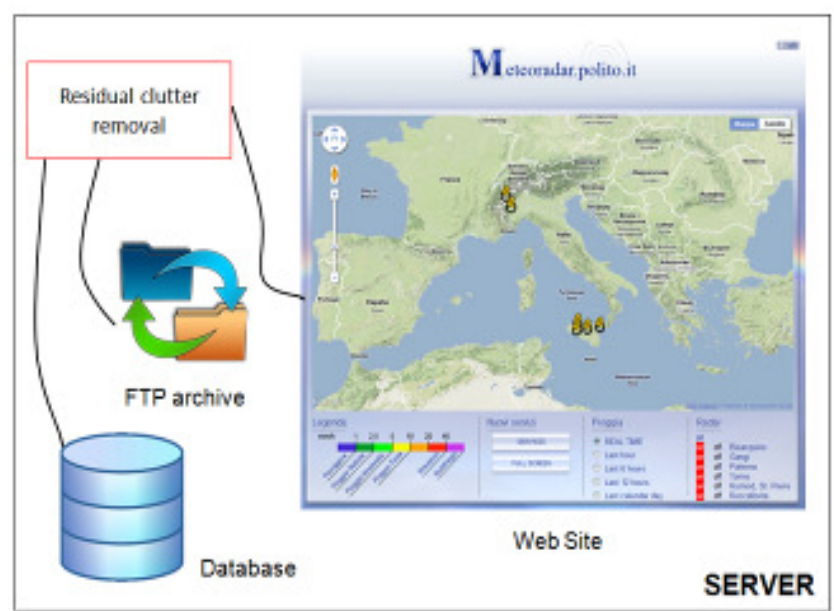

Fig. 2. Data processing scheme at the server

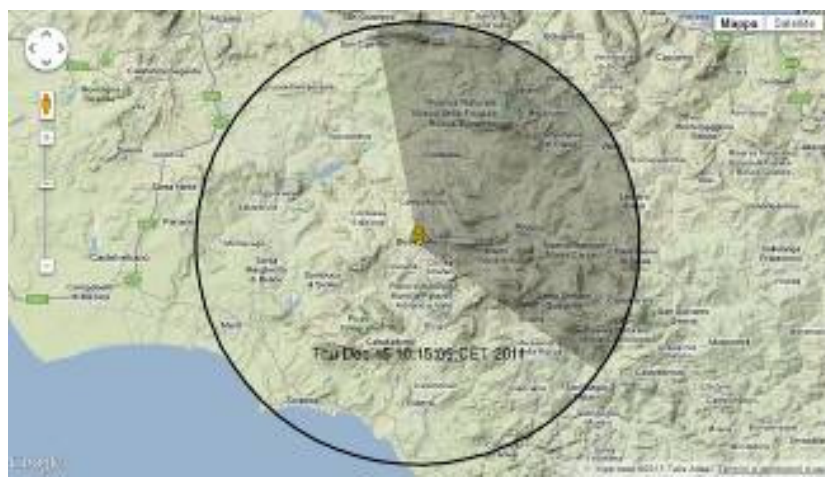

Fig. 3. Map example (no rain) projected over a cartographic system provided by Google $(\mathrm{C}$. The image refers to the radar installed in Bisacquino

(PA). The gray area is the graphical representation of a blanked region.

Following the requirements suggested by institutions responsible for natural hazards preventions some specific web services have been implemented, e. g. : accumulated precipitation over the entire observed area by each radar at different time intervals (every hour, six hours, twelve hours and every day), as shown in Figure 4, production of a specific weekly report, accumulated precipitations in a given userdefined area with an automatic alert output signal if a given threshold is passed (it is possible to implement a simple hydrology balance equation for the same area), time laps representation at different velocities of the last 15 maps in order to visualize the time evolution of the phenomena.

Each service can be accessed by a simple and intuitive web interface.

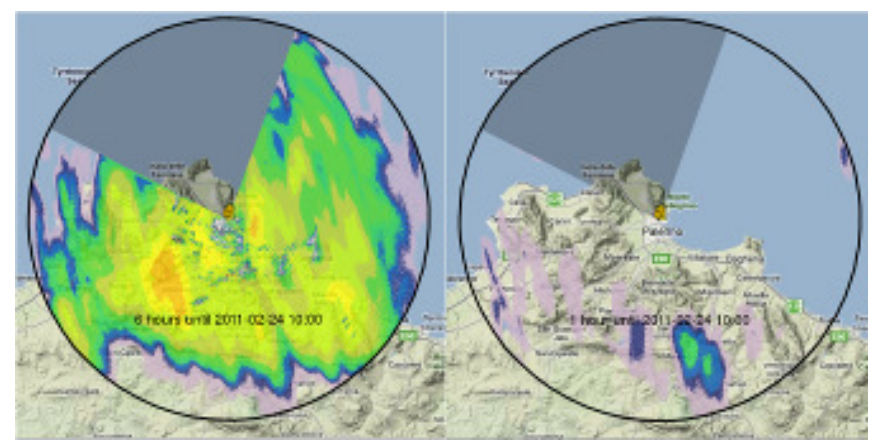

Fig. 4. Rain accumulation maps from the radar installed in Palermo. The left one is evaluated within a time interval of 6 hours and the right one refers to a time interval of 1 hour, in the same day.

\section{NETWORK CALIBRATION}

\section{A. Hardware and software calibration and adjustment}

A continuous and automatic monitoring of the microwave transmission/reception line is performed through a systematic analysis in time and space of ground clutter in clear sky in order to put in evidence significant calibration problems. If necessary, the receiver filter may be adjusted remotely to avoid losses due to the mismatch between the transmitted frequency and the central frequency of the receiver filter. 
Similarly, the operators may modify remotely, through GPRS, not only the constants used in the data processing at the installed radars, but even change the algorithm used in constructing the data maps transmitted to the server.

\section{B. Occultation mask}

The fixed occultation masks have been computed during the first operating period of the radar network. For each radar, a set of rain events has been acquired and at the same time a visibility study has been done using a free DEM [8]. It has been possible to evaluate a visibility-occultation mask for each radar, combining the results of the $360^{\circ}$ radar visibility analysis together with the total cumulative rain map obtained from the set of rain events occurred during the calibration period.

\section{Preliminary radar - rain gauge comparison}

To validate radar network rainfall measurements some comparisons with existing rain gauge networks data have been analyzed. In particular, SIAS (Servizio Informativo Agrometereologico Siciliano) rain gauges have been used. Rain data for comparisons have been obtained computing a temporal integration over a time interval of 1 hour, while radar data have been obtained adopting evidently the same temporal integration and a spatial integration over 1 square $\mathrm{km}$ area centered around the rain gauge. Radar maps values are converted into reflectivity $\mathrm{Z}$ and into rainfall rate $\mathrm{R}$ through the $\mathrm{Z}-\mathrm{R}$ common equation. The fixed $\mathrm{Z}-\mathrm{R}$ relation used here is the one proposed by Rosenfeld in [9], with $a=250$ and $b=1.2$, initially proposed for tropical rain but usable also for intense and persistent rain not only in tropical regions.

Figure 5 shows an example of the comparison between the radar installed in Bisacquino (PA) and the gauge at Giuliana (PA) considering an event on $26^{\text {th }}$ April 2011.

Figure 6 and 7 show other examples of comparisons between the radar installed in Palermo and the gauges of Partinico (PA) and Uditore (PA) considering the rainfall events of 18th February 2011. All comparisons show a good agreement between radar rainfall amount estimation and rain gauge measurements.

\section{CONCLUSIONS AND OUTLOOKS}

The X-band radar network gives accurate rain field monitoring and good rain measurements with high space and time resolution. It provides a set of web services finalized to territory monitoring in order to give alarms with the time advance compatible with the real dimensions of the monitored basins, helping to lower the problems caused by extremely high rainfall events. Other network services (e.g. in [10]) may be implemented, always according to the institutions responsible for natural hazard prevention. The network is still under developments. Future studies will concern the analysis of some of the extreme rainfall events occurred over Sicily, aiming specifically at analyzing the spatial and intensity distribution of extreme events. Massive and systematic radar- rain gauge comparisons will be performed together with $\mathrm{C}$ band radar data in order to put in evidence the improvement in rain fields analysis that can be reached by using these three different observing systems at the same time.

\section{ACKNOWLEDGMENTS}

The present work has been produced as result of a wide research and experimental activity promoted by the local operative unit of CINFAI (Consorzio Interuniversitario Nazionale per la Fisica delle Atmosfere e delle Idrosfere, www.cinfai.it) at Polytechnic of Turin. The activities have been developed in collaboration with Envisens Technologies s.r.l. (www.envisens.com), spinoff of Polytechnic of Turin, and have been promoted by the Civil Protection of Regional Province of Palermo and the Regional Civil Protection of Sicily. A special thank is due to SIAS (Servizio Informativo Agrometereologico Siciliano) for providing us its rain gauge network data.

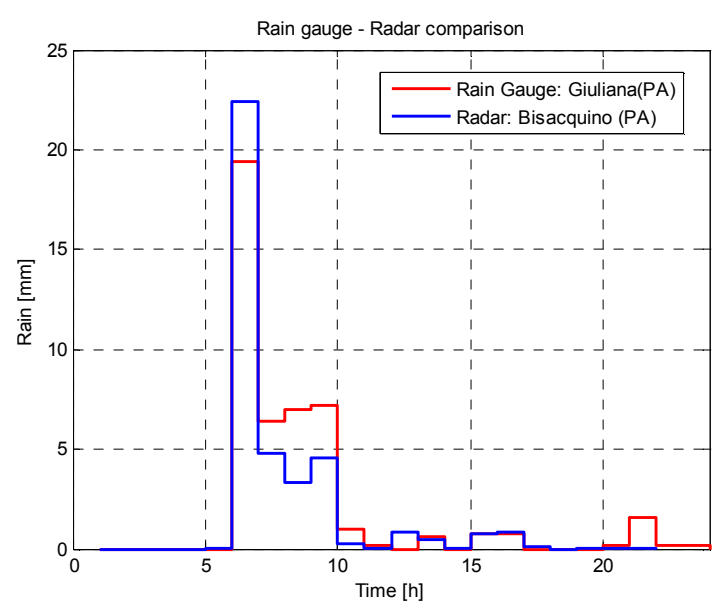

Fig. 5. Example of rain gauge - radar comparison. Day: $26^{\text {th }}$ April 2011 Radar: Bisacquino (PA). Rain gauge: Giuliana (PA)

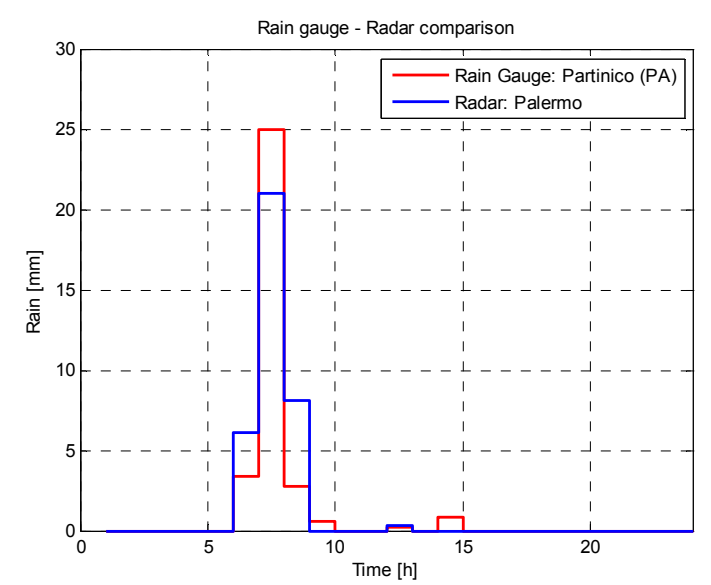

Fig. 6. Example of rain gauge - radar comparison. Day: $18^{\text {th }}$ February 2011. Radar: Palermo. Rain gauge: Partinico (PA) 


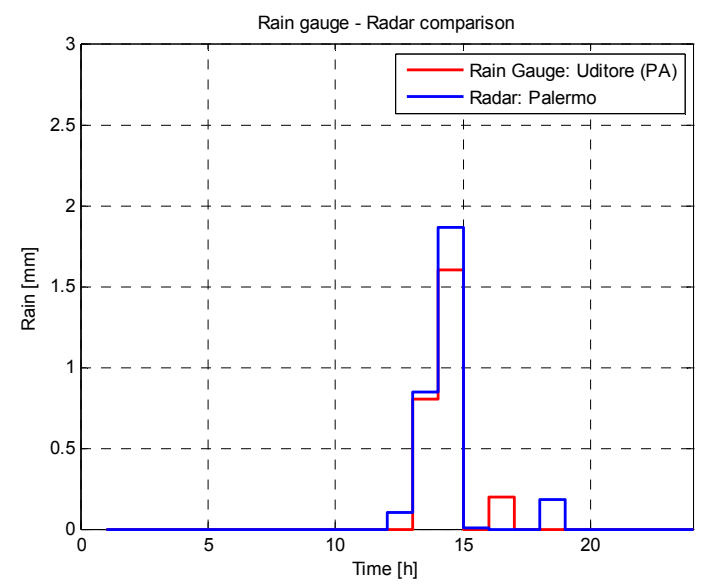

Fig. 7. Example of rain gauge - radar comparison. Day: 18th February 2011. Radar: Palermo. Rain gauge: Uditore (PA)

\section{REFERENCES}

[1] M. Gigliotti, http://www.scienze-naturali.it/ambiente-natura/maltempoe-cattiva-edilizia-cosa-sta-accadendo-alle-nostre-localita-italiane.

[2] A. Fuccello, R. Bove, http://www.meteoam.it/?q=alluvione_Messina Calabria_22novembre2011

[3] D. McLaughlin, D. Pepyne, B. Philips, J. Kurose, M. Zink, D. Westbrook, E. Lyons, E. Knapp, A. Hopf, A. Defonzo, R. Contreras, T. Djaferis, E. Insanic, S. Frasier, V. Chandrasekar, F. Junyent, N. Bharadwaj, Y. Wang, Y. Liu, B. Dolan, K. Droegemeier, J. Brotzge, M. Xue, K. Kloesel, K. Brewster, F. Carr, S. Cruz-Pol, K. Hondl, P. Kollias, "Short-Wavelength Technology and the Potential For Distributed Networks of Small Radar Systems", Bull. Am. Meteorol. Soc., Vol. 90, No. 12, pp. 1797-1817, 2009

[4] F. S. Marzano, E. Picciotti, G. Cinque, M. Montopoli, L. 1a Bernardini, G. Giuliani, E. Anagnostou, M. Anagnostou, Y. Fessas, A. Volpi, A. Telleschi, J. Kalogiros, V. Cazac, R. Pace, F. Sanna, "HydroRad project: integrating X-band mini-radar networks and hydro-meteorological forecast models in Moldova territory", ERAD 2010-The Sixth European Conference on Radar in Meteorology and Hydrology, Sibiu, Romania, September $6^{\text {th }}-10^{\text {th }}, 2010$.

[5] R. Notarpietro, M. Zambotto, M. Gabella, S. Turso, G. Perona, "The radar ombrometer: a portable, low-cost,short-range, $\mathrm{X}$ band radar for rain estimation within valleys", 3rd VOLTAIRE Workshop joint with the 7th European Conference on Application of Meteorology (ECAM7) and the European Meteorological Society Meeting (EMS05), Utrecht, The Netherlands, September 12th - 16th, 2005.

[6] M. Gabella, F. Orione, M. Zambotto, S. Turso, R. Fabbo, A. Pillon, "A portable low cost X-band RADAR for precipitation monitoring in Alpine valleys: analysis of radar reflectivities and comparison bewteen remotely sensed and in situ measurements; Test of a prototype in Friuli Venezia Giulia”, FORALPS Technical Report 3, Università degli studi di Trento, Dipartimento di Ingegneria Civile e Ambientale, Trento, Italy, pp. 52, 2008.

[7] J. S. Marshall, W. M. Palmer, "The distribution of raindrops with size", J. Meteorol., Vol. 5, No. 4, pp. 165-166, 1948

[8] H. Sauvageot, Radar Meteorology, Artech House Publisher, Norwood, MA., 1992.

[9] D. Rosenfeld, D. B. Wolff, D. Atlas, "General probability matched relations between radar reflectivity and rain rate", Journal of Applied Meteorology, Vol. 32, No. 1, pp. $50-72,1993$

[10] M. Montopoli, E. Picciotti, S. Di Fabio, A. Telleschi, A. Volpi, F. S. Marzano, "X-band weather radar monitoring products at urban scale: spatial calibration hail detection and tracking accuracy evaluation", ERAD 2010 - The Sixth European Conference on Radar in Meteorology and Hydrology, Sibiu, Romania, September $6^{\text {th }}-10^{\text {th }}, 2010$. 